\title{
Use and influence of composite indicators for sustainable development at the EU-level
}

\author{
Léa Sébastien ${ }^{\mathrm{a}}$, Tom Bauler ${ }^{\mathrm{b}, *}$ \\ a Université Toulouse II-le Mirail, GEODE Research Center (Environmental Geography), UT2-Le Mirail, Maison de la Recherche, Laboratoire GEODE, 5 allées \\ Antonio Machado, 31058 Cedex 9, Toulouse, France \\ ${ }^{\mathrm{b}}$ Université Libre de Bruxelles, Institut de Gestion de l'Environnement et d'Aménagement du Territoire, Centre d'Etudes du Développement Durable, ULB - \\ IGEAT (cp130/02) 50, Avenue FD Roosevelt, B-1050 Brussels, Belgium
}

\section{A R T I C L E I N F O}

\section{Article history:}

Received 23 December 2011

Received in revised form 29 March 2013

Accepted 20 April 2013

\section{Keywords:}

Composite indicators

Policy use

Sustainable development

European Union

Governance

\begin{abstract}
A B S T R A C T
Considering the on-going strive towards new, alternative indicators to measure our societal development pathways, and the fact that policy indicators remain largely enigmatic with regard to their patterns of embeddedness in institutional decision-making processes, it appears necessary to work towards reducing our lack of understanding of their interactions with policy-making. In the present paper, we focus on exploring the significance of composite indicators for policy making in the particular policy environment of the EU-institutions. Our research is underpinned by the conviction that such indicators are not systematically used directly, but have an indirect influence on policy making that needs to be better understood. Our analytical framework - in order to analyse the ways in which composite indicators enter policy processes - is characterised by the distinction between the 'use' and the 'influence' of indicators on the one hand, and on the other hand between 3 types of factors: indicator factors, policy factors and user factors. Our empirical results show that while most of the academic attention and political debate around indicators has tended to focus on 'indicator factors', such quality attributes actually mattered relatively little in our setting as determinants of indicator influence. This rejects the idea that the robustness of evidence would lie exclusively in its technical quality and in the independence of its producer, and instead calls attention to the processes of evidence-construction. Simultaneously, 'user factors' (beliefs and representations of policy actors) and 'policy factors' (institutional context) were crucial as explanatory factors of the policy mechanics we identified.
\end{abstract}

(c) 2013 Elsevier Ltd. All rights reserved.

\section{Introduction}

We live in a period of indicator abundance in virtually all policy domains, and with an intensifying public and expert-based debate (Stiglitz et al., 2010; OECD, 2011; CEC-COM, 2009; FAIR, 2008) on the choice, configuration and development of indicators to measure our societies' development. Nevertheless, policy indicators remain largely enigmatic with regard to their patterns of embeddedness in institutional decision-making processes (Innes, 1998; Ayres, 2000; Gudmundsson, 2003; Lehtonen, 2004; Hezri and Dovers, 2006; Rosenström, 2006; Boulanger, 2007; Rydin, 2007; Turnhout et al., 2007; Bauler, 2012).

Considering the on-going strive towards new indicators, reducing our lack of understanding of their interactions with

\footnotetext{
* Corresponding author. Tel.: +32 26504924.

E-mail addresses: lea.sebastien@univ-tlse2.fr (L. Sébastien), tbauler@ulb.ac.be (T. Bauler).
}

policy-making appears necessary. We still know little about how and why policymakers, stakeholders and citizens use indicators in general, and composite indicators in particular and, more importantly, whether the indicators actually influence policy and society at large. In the present paper, we focus on exploring the significance of composite indicators for policy making. These particular indicators aggregate diverse information on a sector area, and result in fine in providing the basis for its ranking, which in turn often allows to compare the outcomes of public policies. Composite indicators are repeatedly described as being straightforward to use as signal-makers. Because of their apparent 'simplistic' design and the unambiguous message they advance, composites are meant to impact on the specific fringe of high-level policy-makers as well as on the general public/stakeholders. These indicators have the advantage of being encompassing, but the disadvantage of being difficult to decrypt and analyse, because they highly condense messages, i.e. reality. If the 'offer' of composite indicators in the sustainable development domain (SDI-C) is substantial, i.e. the sheer number of SDI-C which are developed and published, our generic 
research question is to attempt to qualify the 'demand', i.e. the reception of the messages by those policy actors who act within the policy arenas (Sebastien and Bauler, 2010).

What's the significance of composite indicators for sustainability (SDI-C) at EU-level? We aim to characterise the uses (including processes of 'non-use' or 'misuse') and influence of SDI$C$ by decision-makers at the EU-level and to understand the social network in which these indicators are embedded. Empirically the focus on composite indicators has a double advantage over disaggregated indicators or indicator lists: composite indicators have at least one relatively clear target-user group (i.e. high-level policy makers) and a relatively specific function (i.e. to draw attention to a policy problem). These inherent characteristics of composite indicators help to circumscribe the boarders of an empirical exploration of how composite indicators link to policy. Our field of exploration is further delimited by the policy domain to which the composite indicators we explore belong; we exclusively investigate the linkage to the 'sustainable development' policy agenda at the European decision-making level. This case study has been studied in the three-year EU-funded research project POINT (policy influence of indicators), which examined the roles that environmental and sustainability indicators play (or indeed fail to play) in policymaking in different countries, domains and at various scales. Our research is underpinned by the conviction that indicators are not systematically used directly but have an indirect influence on policy making that needs to be deeply studied. Our empirical exploration of the use and influence of composite indicators in policy-processes intends to elucidate the mechanics which built up around indicators as being part of governance processes, and, the 'politics of policy indicators' (Bauler, 2012).

Section 2 below presents the theoretical context, followed by our framework and methodology in Section 3. Sections 4 and 5 are devoted to our results and discussions.

\section{Theoretical contextualisation}

Indicators have been defined as "variables that summarise or otherwise simplify relevant information, make visible or perceptible phenomena of interest, and quantify, measure, and communicate relevant information" (Gallopin, 1996, 108). As a specific form of operationalising the concept of evidence-based policy, indicators are seen to serve multiple functions, in particular those of communication and awareness-raising (Rosenström and Lyytimäki, 2006, 33), providing early warning functions, political advocacy, and improving the quality of decisions. Whichever the primary objective, indicators are expected to reduce ambiguity. As knowledge-agents, indicators are expected to communicate evidence in a form suited for policy actors by simplifying the description of complex systems, either through reducing the number of key variables observed (McCool and Stankey, 2004, 295) ${ }^{1}$ or by building clear, unambiguous and well-defined visions of the desired future (Hardi and Zdan, 1997).

These expectations of indicator functions are habitually rooted in a rationalistic and linear conception of the instrumental role played by knowledge in decision-making, entailing the assumption that more efficient policy outcomes will result if robust, datadriven, presumably objective and value-free evidence is made available for policymakers, in a simplified and synthesised format. By clarifying issues and reducing scientific uncertainties, indicators would hence provide a shared factual basis for policy discussions, and enhance the rationality of decision-making and the quality

\footnotetext{
${ }^{1}$ McCool and Stankey $(2004,295)$ argue that "a basic purpose of indicators is to reduce complex, poorly understood systems to a limited number of variables that presage impending changes in life support and management systems."
}

of decisions ${ }^{2}$. The underlying logic can therefore be described as one of better information (because robust and simple) for better decisions (because effective and efficient). In this perspective, indicators are frequently conceived of as consensus-building tools essential instruments in attempts to pacify conflict and domesticate controversy, which are seen as time-consuming obstacles to efficient policymaking. Such domestication would be achieved through the establishment of norms, standards, criteria and procedural rules for monitoring and regulation (Chateauraynaud, 2011, 195). The linear model that sees indicators exclusively in such an instrumental role still prevails as the main narrative in policy practice (Owens et al., 2004). However, research on knowledge use (Vedung, 1997; Weiss, 1999) has demonstrated that knowledge seldom plays such a straightforward role in policymaking, but far more often influences policies through indirect and largely unforeseen pathways, gradually shaping frameworks of thought or serving as ammunition in political battles. In contrast with the dominance of rationalistic approaches to the analysis of indicators, our paper draws attention to the various indirect ways in which indicators come to exert their influence.

\section{An analytical framework for the exploration of use and influence of SDI-Cs}

\subsection{Distinguishing between use and influence}

The first level of our analytical framework to analyse the ways in which indicators enter policy processes is the distinction between the 'use' and the 'influence' of indicators. The separation of use and influence draws on evaluation research, notably on Mark and Henry (2003), who argue that while indicator use does not automatically lead to impact, likewise an indicator can significantly influence policy and society without anyone actually consciously 'using' the indicator. We define use as the concrete act of handling the indicators in a policy context, whereas influence occurs through dialogue and argumentation (Valovirta, 2002) - either during the process of elaboration of indicators or subsequent to their release. While 'use' traces back the original objectives, intentions and strategies pursued by actors handling the indicator, 'influence' enables one to identify the ways in which indicators interact with policymaking. Influence is therefore close to the concept of portée (in english: 'reach' or 'extension'), which Chateauraynaud (2011) employs to qualify the role, status, and the actual strength of an argument in a public controversy. Indicator 'influence'/portée can concern the targeted policy or broader processes in society, such as administrative structures or the operation of democratic institutions. It can entail new or reconfirmed decisions and actions, shared understandings, networking among policy actors or changes in the legitimacy of policy actors (Mark and Henry, 2003; Lehtonen, $2005,173)$. Often, however, the types of influence of indicators might be very different from the intended use. For instance, indicators might be developed with the objective of monitoring the evolution of a particular variable (say, the share of solar power in national energy production) deemed to provide information on policy effectiveness (in promoting the production of renewable energy). However, the publication and use of the 'solar power'indicators might trigger a much wider than intended discussion on

\footnotetext{
${ }^{2}$ Examples of such perception of indicators as objective measurement tools are easy to find in the literature. The developers of the Environmental Sustainability Index (ESI) argue that "[t]he ESI moves us towards a more analytically rigorous and data driven approach to environmental decision making" (Devitt and DeFusco, 2002), while the organisation "Redefining Progress" (2003) declared that it sought to "measure the real state of our economy, our environment, and social justice with tools like the Genuine Progress Indicator and the Ecological Footprint".
} 
the environmental impacts of the production and recycling of solar panels, and hence raise questions about their public acceptance an outcome in terms of the influence of the indicators which is at least partly contrary to the objectives of the solar power advocates. Summing up, 'influence' enables the identification of the ways in which indicators interact with policymaking, whereas 'use' traces back the objectives and intentions pursued by actors handling the indicator.

Use and influence have their instrumental dimensions (as seen earlier) but, more importantly for our paper, also their conceptual and political dimensions. Conceptual use and influence occur when indicators help to constitute a broad information base for decisions by shaping conceptual frameworks, mostly through dialogue, public debate, and argumentation. An indicator, or a set of indicators, hence provides general background information, leading to "enlightenment" among policy actors, i.e. "the percolation of new information, ideas and perspectives into the arenas in which decisions are made" (Weiss, 1999), and shared understandings (Innes, 1998). In this way, indicators would affect decision-makers' and other policy actors' problem definitions, and provide new perspectives and insights, rather than targeted information for a specific point in decision-making, or to a hypothetical single decision-maker. Given the complexity and uncertainty as well as the diversity of normative standpoints involved in policies concerning sustainable development, it can be argued that sustainability indicators most often provide shared concepts and open up a range of alternative perspectives, rather than produce conclusive assessments of specific policy options.

Lastly, indicators are frequently subject to and generate overtly political use and influence, helping to justify or legitimise policies, decisions and actors or postpone decisions. Ortega-Cerdà (2005) mentions the symbolic function of the processes of knowledge creation as substitutes for action or as a delaying tactic. Knowledge is then used to justify pre-determined positions, in order to persuade politicians, civil servants, stakeholders or public at large typically about policy plans that are already well on their way towards implementation (Hezri and Dovers, 2006; Patton, 1997). Indicators would hence constitute a façade intended to give the impression of a rational organisation that sets goals, is prepared for change, has a serious and competent management, and takes rational decisions on the basis of data which is it about to construct (Pollitt, 2006). In extreme cases, indicators can be 'misused' by distortion or the omission of significant elements (Weiss et al., 2005). However, given the essential role of justification and persuasion in political decisionmaking (Valovirta, 2002), far from mere illegitimate manipulation, political use and influence can also constitute an essential source of democratic legitimacy, or a form of advocacy for socially progressive objectives, such as sustainable development (Parris and Kates, 2003; Holden, 2008).

\subsection{Identifying explanatory factors}

The second level of our analytical framework strives to explain the observed use and influence patterns through three explanatory factors, following Pregernig (2000), who suggested that knowledge uptake is governed by three factors: (a) the information itself (what we call the 'indicator factors', related to the various quality attributes of the indicator), (b) the knowledge and experience of the receiver (here, the 'user factors', notably the 'repertoires' (van der Meer, 1999) of the actors involved), and (c) the external settings ('policy factors', denoting the general policy context).

'Indicator factors' include the quality and structuring of data, selection of the variables, weighting schemes, timeliness, robustness of the methodology, availability of accurate and appropriate data sources, methods of communication, construction, aggregation and presentation of indicators. The criteria relating to the quality of indicators include the conventional determinants of scientific data: validity, reliability, specificity, and sensitivity to changes in the factor of interest. The underlying assumption here is that when information is "relevant, timely and comprehensible, it will be used" (Romsdahl, 2005).

'User factors' describe the repertoires - a concept that encompasses actor expectations, belief systems (Sabatier, 1991), mental models and the more operational codes and practices of organisations. Repertoires can be conceptualised as "stabilised ways of thinking and acting (on the individual level) or stabilised codes, operations and technology (on other levels)" (van der Meer, 1999, 390). At the individual level, an actor positions himself personally in relation to an indicator after having read, digested and interpreted it (Hezri and Dovers, 2006); at the collective level, repertoires relate in particular to the degree to which the use of indicators is part of an organisation's operational routines. A crucial element of user factors relates to the implicit or explicit conceptual model underpinning an indicator: to what extent does the way in which an indicator frames the reality and the problems in question correspond to the conceptual framework of the users and other actors involved? Repertoires are important in that they govern the choices that users make among the multitude of information on offer.

Finally, the type and degree of use and influence of indicators is affected by the general political context in which the indicators are being developed and used. Such 'policy factors' concern the meta-setting within which indicators are being used and produced, and include, in particular, the long-term framework conditions, the short-term shifts in governing coalitions and the characteristics of the policy issues at stake. An important aspect of the "policy factors' is the institutionalisation of indicators, that is, the setting up of procedures and practices that allow for an indicator to become a reference in policy processes, and which legitimises and formalises the methods and concepts underpinning the indicator (Innes, 1998). The degree and type of use and influence that an indicator engenders are shaped by its relevance for specific policy objectives and policy processes. Following Kingdon (1984), one could hypothesise that the use and influence of an indicator would be compromised if the policy problems it describes do not adequately match with the prevalent policy ideas on the one side, and do not face a favourable political environment on the other.

These three sets of factors relate to three distinct, while interdependent, levels of possible analysis. Policy factors depend largely on the policy domain, user factors relate to the policy actors' perceptions, while indicator factors refer to the nature of the object, i.e. the indicator. These three levels form the basis for our analysis of the use and influence of SDI-C in policymaking.

To sum up (see Fig. 1 below), the degree to which an indicator is used and/or influences policy instrumentally, conceptually or politically depends to varying degrees on indicator, user and policy factors. Our objective here is to depict the role of each explanatory factor in the various types of policy uses and influences of SDI-C.

\subsection{Empirical methodology: a qualitative approach to explore indicator use and influence}

We focused our empirical exploration on a set of 12 SDI-Cs, each of which can be classified into one of the three dimensions of sustainable development:

- Social sphere: main focus on the Human Development Index (HDI), additional attention was given to the Happy Planet Index, Worldwide Governance Indicator, Human Well-Being Index. 
L. Sébastien, T. Bauler / Ecological Indicators 35 (2013) 3-12

\begin{tabular}{|l|l|l|l|}
\cline { 2 - 4 } \multicolumn{1}{c|}{} & \multicolumn{3}{c|}{ Use and Influence } \\
\cline { 2 - 4 } \multicolumn{1}{c|}{ Instrumental } & Conceptual & Political \\
\hline Indicator factors & & & \\
\hline User factors & & & \\
\hline Policy factors & & & \\
\hline
\end{tabular}

Fig. 1. Analytical framework.

- Environmental sphere: main focus on Ecological Footprint (EF), additional attention to Living Planet Index, Ecosystems Wellbeing Index, Environmental Performance Index.

- Economic sphere: main focus on Genuine Savings, (GS) additional attention to Index of Sustainable Economic Welfare, Corruption Perception Index, Gini Index.

The three headline SDI-Cs (HDI, EF, GS) were prioritised by the EU-level 'Beyond GDP'-process (today relabelled as 'GDP and beyond') as important featuring indicators ${ }^{3}$. Empirically, we deployed 3 perspectives to our qualitative analysis: an individual level (via face-to-face interviews); an interpersonal level (using a 'participant-observer' approach), a collective level (via document analyses).

In order to depict the use and influence of SDI-C at the individual level, an obviously important perspective to be explored when trying to grasp the perception of policy-makers with regard to indicators, we conducted 24 semi-structured interviews with high- to mid-level policy-makers from the European Environment Agency, DG Environment, DG Research, DG Education, DG Internal market and EUROSTAT. The interview guide developed around the following themes: decision- and policy making processes; sustainable development and well-being indicators; the pertinence of indicator aggregation; the configuration of an ideal SDI-C; the policy targets, policy objectives and pertinent scale of SDI-C; the social network around SDI-C; the interest, concern and trust towards SDI$\mathrm{C}$; the 'demand'-characterisation for SDI-C; the legitimacy criteria for SDI-C.

In parallel to the face-to-face interviews, the participantobserver approach has been implemented in a series of preidentified workshops and (international) conferences specifically dedicated to debate the issue of EU-level indicators in 2009 and $2010^{4}$. The objective was to observe interactions, dynamics, discourses and representations of policy actors at these events, with the aim to grasp what sort of messages policy actors publicly defend, argue, and debate on the matter of SDI-C. Our empirical setting enabled us to directly observe - via our focus on SDI-C the dispute of interpretations within the policy arena of SD (i.e. what is the 'vision' of SD at EU-level?), and to indirectly observe the dispute between policy arenas (i.e. where does SD stand with regard to other 'visions' of the European development pathway?). We are shifting from the individual level of perceptions (which was the focus of our face-to-face explorations) towards the interpersonal level of the shared understanding of the use and influence of SDI-Cs within policy processes, e.g. the role of SDI-Cs in the processes of argumentation and dialogue among actors (persuasion, legitimisation, criticism...) (Valovirta, 2002).

3 http://www.beyond-gdp.eu/indicators.html.

${ }^{4}$ Such as the Sustainable Development Indicators working group within EUROSTAT (Luxemburg, 2009-2010); the OECD Worldforum (Korea, 2009); the conference on Beyond GDP and Ecological footprint (Brussels, 2009); the EPIGOVproject's (Environmental Policy Integration and multi-level governance) final conference (Brussels, 2009).
A third level of analysis was implemented through document analysis of formal, strategic policy documents ${ }^{5}$. These documents speak for the collective level, i.e. they are collectively, politically or scientifically accepted policy documents with an influence on the configuration of policy arenas. The percolation of SDI-C was traced throughout the entire policy processes by concentrating on the identification of indicator-related content within these policy documents. The collective level examines outcomes in terms of policy decisions and actions, shared beliefs and understandings, legitimacy of policies and actors, agenda-setting and network formation (Mark and Henry, 2003).

When exploring our analytical framework, which collates 3 factors vs. use/influence of SDI-Cs, through these 3 different lenses of the personal, interpersonal and collective levels, we were aiming to depict the EU-level policy-makers' perceptions (personal level), their debates, discourses and conflicts (interpersonal level) and the formal outcomes of the policy processes (collective level via document analyses).

In the following, our results are organised in two parts. First, we develop our results over the three levels of analysis (individual, interpersonal, collective). Subsequently, we discuss the roles of the three different identified explanatory factors of indicator use and influence (i.e. user, indicator, policy factors).

\section{Results (part 1) - from perceptions to policy outcomes: little evidence of indicator use}

\subsection{Individual level: identifying 3 confusions}

The individual level developed into an important level of reading when it comes to interpreting the use of indicators. In the end, it is individuals who are meant to operate, i.e. to use, the indicators in their daily live as policy-makers. The fact that most of the interviewed policy-makers had no memory of having "used" SDICs in their professional setting appeared through the interviews to originate from 3 confusions.

First, most of our EU-level policy-makers had a poor factual knowledge of SDI-Cs in general. The interviewed policy-actors generally had some basic knowledge only of the Ecological Footprint (EF) and the Human Development Index (HDI). They often declined to express their opinions even on these SDI-Cs, arguing that they were not specialists of the sustainable development policy agenda. Nevertheless, most of the interviewees explicitly stated that they were interested and actively followed the European-level "Beyond GDP"-process; this situation results from a confusion by the interviewees to adequately separate a policy process on changing the indicators from a policy process on changing the socio-economic characteristics of our societies (i.e. "Beyond Growth"). The lack of factual knowledge as well as of awareness of the nature of the SDI-C related policy-process can simply be a sign of information over-

\footnotetext{
5 Lisbon strategy indicators; EU Sustainable Development Strategy (SDS) indicators; DG Environment indicators; Euorpean Environmental Agency (EEA) indicators; GDP and beyond indicators; EU2020 indicators; the Stiglitz-Sen-Fitoussi report.
} 
flow: too many processes linked to too many indicators. On the other hand, it is evident from the interviews that - at least partly - power relations and vested interests may induce policy-makers to state non-existing ignorance and confusion (Sager and Ravlum, 2005; Flyvbjerg, 1998).

Second, the interviewed policy-makers did not feel directly concerned by composite sustainability indicators. Again, this appears partly surprising because SDI-Cs are specifically designed for both policy-makers and society at large by aiming to provide a quick message to non-specialists. Indicators of a more disaggregated nature were claimed to be more influential than SDI-Cs. At this level, the non-use of SDI-Cs can be explained by the fact that policymakers and the more general public effectively have different needs in terms of indicators; that they should not be confused as an identical target group. Tailoring SDI-Cs for one or the other could be essential. Indeed, the indicator producers were often seen as being too ignorant of the specificities of the target group (i.e. the policymakers), being in general disinterested in the way in which their indicators were received by the targeted users and about the type of use that their indicator(s) might engender.

A third explanation for the minor (instrumental) use of SDICs is grounded in the acknowledgement by all our interviewees that SDI-Cs can be confusing for being at the same time general 'world visions' and targeted evidence for policymaking. Our interviewees argued that while indicator producers seek in principle to match information-provision with policy-making needs in order to allow timely and appropriate decision-support, SDI-Cs were advocating a certain 'world vision' (e.g. the finiteness of environmental resources), which is necessarily partisan and particular to a specific indicator producer. The policy-makers strongly underlined the inherently subjective nature of indicators, arguing that just about every step in indicator production and diffusion is arbitrary, a "matter of choice made by one particular actor at one particular time

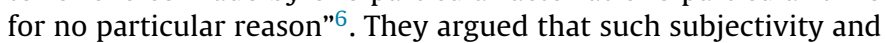
arbitrariness is even stronger for complex and poorly defined policy issues such as sustainability, which remains subject to numerous rival attempts of definition.

\subsection{Interpersonal level: evident conflicts between policy-makers}

The European Union's institutions are a rather unifying policy structure; Directorate-Generals, European Parliament, European Council, European Agencies co-develop policies and the more important of them are decided on a common basis. However, during policy development and configuration - but also when it comes to justifying passed decisions - debate does of course prevail among policy makers, and it appears in these processes that our target indicators are 'dis-unifying' tools. SDI-Cs stir the policy debates rather than helping to settle them. The participant-observation of a series of high- to mid-level policy events (e.g. conferences, workshops, working groups) allowed to identify the nature of the conflicts between policy-makers that are fought with the help of SDI-Cs. This discourse-enhancing characteristic of SDI-Cs can be shown through the fact that a relatively unambiguous competition exists between the various indicators as proposed by specific DGs, Institutions and Agencies. The observations revealed important inter-institutional conflicts about choice, support and adequacy of potential SDI-Cs, to an extent where individual EU-policy-makers appear to be less in opposition with other, non-institutional stakeholder groups (e.g. NGOs) than with their direct colleagues from within EU institutions.

When looking closely, the conflicting debate on SDI-C mirrors the fact that individuals in different EU-institutions carry

\footnotetext{
${ }^{6}$ Quote of an interviewee.
}

differentiated representations about the meaning of sustainable development. Weiss (1999) and Leknes (2001) purport that the policy influence of indicators is likely to be greater in consensual policy domains of 'professional' character, as well as on policy issues that have reached a status of high institutionalisation. Hence, despite the fact that the EU-level has institutionalised 'Sustainable Development' (SD) as one of its overarching policy goals through the development of the EU-Sustainable Development Strategies (2001 and 2006), policy use of SDI-Cs might well be hampered because of the lack of consensus on the meaning and content of SD as a policy idea or policy domain. One of the alleged benefits of indicators is their ability to provide focus and to enhance shared understanding, for example around the goals of an organisation (Van Der Knaap, 2006). In the case of SDI-Cs at the EU-level, this mechanism does not appear to unfold unambiguously; the policy arena of the EU-Sustainable Development Strategies seems to allow the confrontation of different 'world visions', where the extent of use of SDI-Cs appears to depend mainly on their potential for enhancing conflicts. One of the procedural consequences in terms of policy outcomes is the difficulty of EU institutions to propose and agree on a common set of composite featuring indicators.

\subsection{Collective level: lack of appearance for lack of coordination}

The document analyses unambiguously showed that SDI-Cs are very rarely occurring even in the strategic, relatively vague documents which were produced for the process around the EUSDS. Quite directly, this absence of SDI-Cs can simply be routed in the fact that "there is currently no comprehensive environmental indicator that can be used in policy debates alongside GDP" (CEC-COM, 2009: 433), and that SDI-Cs are quite popularly shelved in the environmental domain. A series of inter-institutional debates over methodological issues around SDI-C, as well as around the potential policy acceptance of composite indicators per se, is implicitly apparent in the screened EU-level documents. But the EU-Commission services (ahead of which Eurostat) continue to prefer a wide list of non-aggregated indicators, complemented by a list of headline indicators.

To a certain extent, EU-institutions recognise the existence and potential of SDI-Cs, but without using them directly as a reference point in their publications. The document analyses reveal not much more evidence on the debate around the 3 targeted main SDI-Cs than stating that UNDP is at the origin of the 'HDI', that the World Bank calculated 'Genuine Savings', and that several NGOs developed the 'Ecological Footprint' (CEC-COM, 2009: 433). Other relatively obvious SDI-C candidates, such as the 'Index of sustainable economic welfare' (ISEW), the 'Living planet index' (LPI) or the 'Human wellbeing index' (HWI), do not appear at all in official EU documents.

While SDI-C are thus widely ignored in strategic EU-documents, the wider policy arena is dedicated to the renewal of indicators, i.e. states its engagement to replacing or complementing GDP and using alternative indicators. The EU-institutions run their 'Beyond GDP/GDP and beyond' process, cooperate with OECD on the redefinition of the 'Measure of social progress', and explore methodological avenues such as ecosystem services, material and social accounting. The Stiglitz-Sen-Fitoussi report (2010) has supported the debate within the European indicators' landscape, developing similar conclusions as the Commission's "Beyond GDP"-communication: "GDP does not measure environmental sustainability or social inclusion and these limitations need to be taken into account when using it in policy analysis and debates. The overall aim is to develop more inclusive indicators that provide a more reliable knowledge base for better public debate and policy making" (CEC-COM, 2009: 433).

The lack of use of SDI-Cs can also be related to the lack of effective coordination and harmonisation of policy processes across the 
various EU-institutions in their specific indicator work, and with regard to SDI-Cs in particular. The message from the EU on sustainability appears diffuse and unclear, and different indicator sets, based on partially contradicting conceptualisations of sustainable development, are proposed by different $E U$ institutions ${ }^{7}$. As a result, the EU policy on SDI-Cs remains characterised by multiple policy streams that seem to have little contact with each other (JRC, 2010). Even though individual indicator frameworks were elaborated separately, i.e. intra-institutionally, many of the highlighted policy-themes overlap. As a result, many indicators are common to different frameworks. EU policymakers are potentially confronted with indicators that cover more than 30 policy-themes and with more than 250 indicators that are meant to assist them to assess policies.

\section{Results (part 2) - discussing influence against user-, policy- and indicator-factors}

\subsection{User factors: explaining the conceptual influence of SDI-CS}

From the above, it occurs thus that SDI-Cs are hardly used instrumentally. SDI-Cs are nevertheless identifiable to be at the origin of indirect, conceptual influence on policy-makers. Our empirical explorations reveal that SDI-Cs at EU-level tend to be used as ammunition by policy actors, notably during their efforts to legitimise specific political and societal positions, and in particular when arguing for or against specific visions and interpretations of sustainability. SDI-Cs are tools which help to shape and share visions, and can therefore be labelled 'framework indicators' or 'framing indicators', whose aim is to shape frameworks of thought, mobilise action, as well as to shape and generate awareness and symbolic images (Weiss, 1999; Amara et al., 2004). Innes and Booher (2000) purport that "indicators do not drive policy. People are not suddenly converted because they are confronted with data, no matter how expertly or how collaboratively designed. Compendia of indicators are not used by policy makers as aids to decision". Their generic finding appears to be applicable to the specific case of SDI-Cs at the EU-level. The implemented 3-fold empirical explorations show that SDI-Cs could shape policymakers' worldviews, and thereby potentially influence future decisions in a rather indirect way. Rather than relying on theories or being linkable to specific models of the human-nature system, which would allow to question, quantify and organise the causalities within this system, SDI-Cs can provide a conceptual framework, open for interpretation and application, that helps to organise diagnostic and prescriptive inquiry, and can provide a form of 'meta-theoretical language' enabling a comparison between theories (Ostrom, 1999). Such conceptual framework indicators pursue the objective to stimulate information flows that eventually will lead to collective understanding of emerging sustainability patterns (Sonntag, 2010). In this sense, it appears adequate that our set of empirically explored SDI-Cs are theory-driven and rely on a strong conceptual language, allowing discussion on emerging paradigms rather than providing unambiguous and targeted policy advice with regard to causalities. The framework indicators appear to affect decision-makers' problem definitions, and provide new perspectives on - and insights into - the problem area, instead of providing information for a specific moment of decision, or to a hypothetical single decision-maker. SDI-Cs at EU-level produce primarily intangible effects (Gahin et al., 2003), fuelling debates and helping to enlighten policy actors on sustainability-related issues. SDI-Cs are not policy tools in the sense

\footnotetext{
7 The different indicator sets are apparent via the EU Sustainable Development Strategy, the EU2020 Strategy, the Lisbon Strategy, and the set of indicators published and profiled by DG Environment.
}

that they would constitute directly applicable evidence for policymaking, but can instead be considered as conceptual references that inform broader policy processes (Illner, 1984).

In these realms, user factors are of a particular importance in understanding and in allowing the occurrence of this conceptual influence of composite sustainability indicators. As framework indicators, i.e. evoking particular paradigms on SD, SDI-Cs need to enable policy-makers to question stabilised codes and repertoires and open new ways of representing reality to them. Our qualitative approach revealed that the acceptance of such framework indicators by policy-makers is primarily conditioned by the level of resonance of the indicator itself with the repertoires of its users. The image of SDI-Cs being ammunition to the legitimisation of positions in on-going policy debates appears thus to be particularly supported here.

\subsection{Indicator factors: initialisation of policy debates via discussing the quality of SDI-CS}

Contrary to the high degree of attention which is traditionally given by the community of indicator producers to the consolidation of the technical and methodological robustness of indicators, our qualitative exploration of the influence of SDI-Cs reveals that 'indicator factors' matter little as direct explanatory factor for the observed use and influence of indicators. In fact, a number of SDI-Cs which are acclaimed for their methodological robustness remain widely unused by policy-makers, while others, which might be of poorer scientific quality, have been adopted to a certain stance by policy-makers at EU-level. No clear scheme of influence arises when the influence of SDI-Cs is explored against the acknowledged (by the policy-makers) robustness of the set of SDI-Cs. However, the empirical, qualitative exploration shows consistency in the explanation of SDI-C influence when plotted against the acknowledged methodological conflicts and interrogations which are raised against specific SDI-Cs. In other words, the more methodological conflicts revolve around an SDI-C, the better indicator factors explain the observed influence. Consequentially, the influence of an SDI-C seems to be conditioned more by the extend of the negotiations between interest groups - a process during which methodological argumentation would be mobilised - than by the effective level of methodological robustness of the SDI-C (Cash et al., 2002, 2003).

More specifically, the interviewed EU-policy makers criticised quite extensively the 'Ecological Footprint' (EF), consistently referring to methodological problems, arguing for its inadequacy during decision-making because EF is not pointing at specific policy options, and regretting the non-inclusion in the EF of many crucial aspects of environmental problems (presumably, for example, issues linked to toxicity). Such 'technical' arguments against the EF have been raised repetitively in literature, and are today hardly a matter of contradiction. Interestingly, however, some interviewees explicitly highlighted the fact that some policy actors would use these methodological issues on EF to ground their opposition to a more formal adoption of the Ecological Footprint by the EUinstitutions, whereas their primary reason of opposition would actually stem from the fact that the adoption of the EF would considerably increase pressure for a radical change of policies - an objective for which Europe would in their view not be ready.

In parallel, a consistent part of our interviewees sees in the HDI a "GDP hybrid, a GDP a bit improved, a GDP with a lesser emphasis on economic variables ${ }^{8}$. In that perspective, HDI might still be viewed as a first step to move away from the tyranny of GDP, but

\footnotetext{
${ }^{8}$ Quote of an interviewee.
} 
HDI is also accused of some form of hypocrisy, only simulating the integration of social aspects into the index while keeping GDP in a very central position. Interviewees acknowledged that the origin of the fairly good image of which HDI profits might actually be linked to the fact that people are generally unaware of the presence and causal influence of GDP within the composite's calculus, leading some of the policy actors to label HDI a "masquerade". Hence, here the actual methodological content of the SDI-C appears to be of minor importance than the image of its content.

In both examples, the methodological construction of SDI-Cs i.e. indicator factors - does thus play a role in the explanation of indicator influence; but quite indirectly. While indicator factors do not seem to exert a positive or negative influence on the choice of the indicators to be used, they actually initiate debate about the configuration of the visions of sustainability the SDI-Cs aim to represent. The minor direct explanatory force of indicator factors can be interpreted according to Pielke (2007) along two dimensions which guide the uptake of scientific and expert knowledge in policymaking processes: $1^{\circ}$ the degree of scientific uncertainty; and, $2^{\circ}$ the potential for value consensus. Typically, SDI-C score equivocally on both characteristics: $1^{\circ}$ they contain a high degree of scientific uncertainty, for instance about the correctness of causalities which materialise in the aggregate indicators; $2^{\circ}$ they reveal a relatively high degree of conflict potential, since each SDI-C carries its specific 'world vision'. On controversial policy issues, with disagreement on values and goals, indicators that enable to narrow down the range of policy options should thus have more potential for influence on policy actors than SDI-C, which tend to exacerbate the conflicts because they allow to support dispute on the representation to be given to the generic policy idea. In other words, the EU-SDS arena is in need for indicators which help to break down the policy idea of SD into policy options, but quite on the contrary, SDI-C tend to open up the debate because the inter-institutional interpretation to be given to sustainable development is not consensual yet in itself. The acknowledged policy influence of SDI-C could thus stem from the fact that their inherent indicator characteristics tend to openup policy visions, rather than enable to close-down the struggle of interpretations.

\subsection{Policy factors: how the nature of the policy arena of $S D$} explains for the influence of SDI-CS

The empirical exploration shows that 'policy factors' are central in explaining the use and influence - or their absence - of indicators. In effect, the meagre reported influence of SDI-Cs could be simply attributed to the nature of the policy domain, seeing in the use/influence dynamics of SDI-Cs a mirror-effect of the dynamics more widely imposed on the policy agenda itself. 'Sustainable development' as a policy agenda is claimed to have at least partly failed to become an overarching reference point in EU-level policymaking. For instance, unlike other EU-level policy agenda, 'sustainable development' is not centred on a narrow set of clearly defined policy issues, but covers a relatively broad range of topics in economic, social and environmental fields. The relatively evasive, undefined nature of the policy-agenda itself would not easily be conducive to provoke an intense flow of use and influence of SDI-Cs.

The overall debate on SDI-Cs, or more widely on alternatives to GDP, is profiting from a considerable and high-level echoing in many EU-institutions. On the ground, it remains however difficult to clarify with policy-makers the exact nature of the 'demand side' for SDI-Cs.

On the one hand, there is a relatively weak stated need for SDI-C at the level of the interviewed policy-makers. SDI-Cs have gained their appreciation not to help policy-makers in designing policies nor guiding specific system interventions, but rather to gain knowledge of emerging or on-going wider policy debates (notably on the necessity to replace or complement the hegemonic GDP). In single cases, SDI-Cs were claimed to be used more classically to compare the performances of regions or member-countries on particular issues. Following Illner (1984), the relative constructed complexity of composite indicators - as opposed to their relative communicative simplicity - may suggest that SDI-C have most relevance during the early descriptive phases of a policy making process, i.e. to identify gross policy problems. The evident fact that there is no plethora of new policy problems, hence of policy debates, that emerges every year on the EU-level could account for the fact that policy-makers express a weak demand for SDI-Cs.

On the other hand, policy-makers state to be submerged by the sheer number of SDI-Cs being proposed from many authors and institutions. In this context, handling SDI-Cs can be particularly demanding for policy-makers, because working with SDI-Cs, i.e. using them, asks them at least implicitly to rally a particular strategic positioning. In this context, SDI-Cs at EU-level are claimed to function as tools to justify a posteriori and support otherwise hardened policy choices, and not as incentive base to change policies or decide on specific policy options.

From our explorations, the 'demand' for SDI-C by EU-level policy-makers cannot be unambiguously qualified, and seems comparatively sparse, undefined, unsure and disparate against the overwhelming presence of the SDI-C 'offer'. An explanatory factor for the disequilibrium between 'supply' and 'demand' of SDI-C can be found at the level of the original motivation to produce and propose SDI-Cs in question. A number of the currently prevalent, 'traditional' composite indicators (among which not the least GDP) were elaborated and produced by institutionally appointed experts upon specific demand by policy-makers facing specific policy situations. These traditional composite indicators can be acknowledged as 'top-down' indicators, built on clear terms of references (co-)defined by their pre-identified 'users'. While such demand-defined composite indicators continue to be elaborated occasionally ${ }^{9}$, the largest part of the offer of SDI-Cs consists of indicators, which are elaborated for policy-makers, but not by, nor with them. The evolution of the more traditional 'top-down'-movement in the definition and configuration of composite indicators has indeed evolved, partly under the influence of the emergence of sustainability-rooted principles such as the acknowledgement of the extension of the knowledge-base beyond the one existing within expert circles (Fraser et al., 2006). Probably more directly, the evolution of our informatics tools and the generalisation of digital access to a broad set of data tremendously facilitated the capacity of non-institutional actors (e.g. NGOs) to engage in the elaboration of composite indicators. As a result, composite indicators are increasingly proposed to policy-makers by a growing variety of non-institutional policy actors ${ }^{10}$. An important number of current SDI-Cs are therefore neither the result of 'top-down', expert-driven institutional exercises, nor are these indicators relying on participatory processes and could be shelved as 'bottom-up', citizen-defined, local and specific indicators (Fig. 2).

In fine, a growing number of SDI-Cs could be labelled 'middleup' and 'middle-down' indicators (Sebastien and Bauler, 2010); they are initiated by stakeholder organisations such as NGOs or Think Tanks, occasionally they originate in independent, academic exercises but which are then further developed, fleshed and communicated by stakeholder organisations. These 'middle' actors are

\footnotetext{
${ }^{9}$ For a recent example, see for instance the on-going construction of material-flow indicators - and the underlying material-flow accounting frameworks - at EU-level. 10 See for instance, the Happy Planet Index by the New Economics Foundation, or the Index for Sustainable Economic Welfare which was originally supported by Redefining Progress.
} 


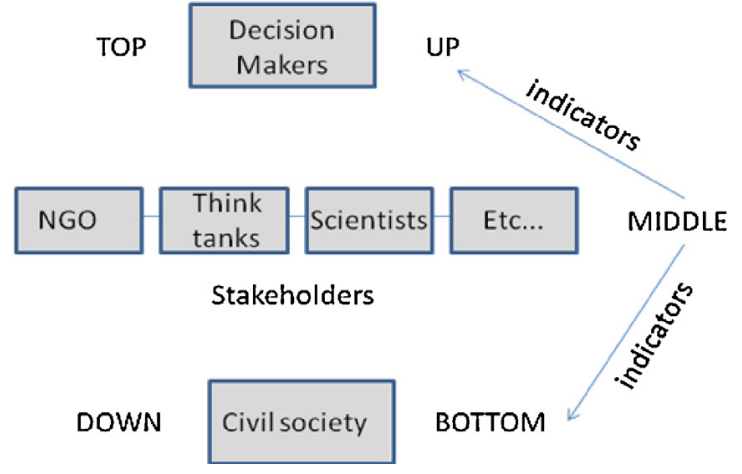

Fig. 2. Diffusion of SDI-C by "middle-actors" to top and bottom actors.

largely independent, non-institutionalised organisations, which function as intermediate actors between civil society at large and the political/institutional policy spheres. In this sense, the 'Ecological Footprint' is a good example: elaborated and conceptualised during a PhD thesis, EF was rapidly taken up by the World Wildlife Fund and is today very controversially discussed (and taken up or rejected) in statistical offices. In a wider interpretation of policy processes, the 'Mittelfeld' actors (i.e. NGOs, Think Tanks, engaged scientists) are the ones who pre-configure the various 'visions' for society (e.g. of the limits of our environmental resources), and who reach out to advocate their visions towards 'top' (i.e. policy actors) and 'bottom' (i.e. society at large). In this process, composite indicators are much-welcomed tools which support the communication of world visions. According to Weiss (1999), the independence of the (information) media, as well as the strength and the status of the NGOs and the civil society in general tend to promote critical discussion in society, thereby potentially increasing the influence of indicators. More particularly, in the case of our set of SDI-Cs, most of the 'Mittelfeld'-actors at the basis of the SDI-Cs have first diffused their ideas (and indicators) horizontally (i.e. between each other) in order to build a network of coalitional actors, with the aim to propose at a later stage their indicators to policy makers ('middle-up') and/or to civil society ('middle-down'). Along this reading of 'Mittelfeld' policy actors coalitioning behind particular indicators, the degree of legitimacy and credibility of the indicator-proposing actors plays a major role in explaining the potential of influence of the indicators (Boulanger, 2007).

In such a context of conflicting and evolving policy arenas, struggling for attention with the support of indicators, the interviewed policy-makers at EU-level clearly stated their curiosity in wellbeing as a new overarching policy concept, and their disinterest in the somewhat overused concept of sustainable development. The socalled Stiglitz report (Stiglitz et al., 2010) helped to initiate this recent reflection on the way societies should think their futures in line with rethinking their indicators. The notions of quality of life, wellbeing, and social progress - and the associated indicators are slowly taking the role of sustainable development as the overarching normative concept of the 'post-GDP society'. Like the 1987 Brundtland report for SD, the Stiglitz-report initiated an emerging reflection on the way Europe should think its future, manage priorities and measure development. Wellbeing and social progress are put in the first row, whereas the core of the SD-conceptualisation, i.e. environmental and resource-related objectives, are relegated into means for wellbeing. This (r)evolution in policy arenas (Boulanger, 2007) - in turn - appears to raise the interest of our policy-makers in the forthcoming wellbeing-related composite indicators; and could explain for some of the stated disinterest in SDI-Cs.

\section{Conclusion}

Sustainability indicators are seldom used directly and instrumentally, but far more often influence decision-making through various indirect and often slow processes. Among the most visible examples of indirect influence were situations in which indicators were used as ammunition in political debates. Experts (whether independent or governmental) often seem to produce indicators without a clear intended use or user in mind, and without regard to the potential influence of the indicators. Combined with the abundance of indicators, this increases the risk that policy makers use only those indicators that suit their own interests, while concealing other, potentially more relevant ones. Mismatch between supply and demand is however not surprising. The SDI-Cs can be described as tools specifically designed by groups of politically engaged experts for purposes of political persuasion.

While most of the academic attention and political debate around indicators has tended to focus on 'indicator factors', such quality attributes actually mattered relatively little as determinants of indicator influence. Sometimes conflicts between world visions were hidden behind methodological debates on indicators. And yet, even though 'indicator factors' were thus not decisive in determining indicator influence, key user groups saw high technical and scientific quality as an essential prerequisite for the determination of their intended use of indicators. Recommendations to ensure that demand and supply meet each other include the suggestion that indicator producers should not devote all their energy to methodological aspects but study the potential receptivity of their indicator. They should also try to metaphorically 'optimise the signal', 'improve the reception' in the policy system or 'increase the bandwidth' (Da Costa et al., 2008) to increase collaboration between producers and users. But as Rice (2003) recalls, in a noisy environment like the one of SD, a perfect signal might be impossible to get. Chateauraynaud (2011) argues that the quality of evidence is defined by the number of controversies that it goes through during its lifetime. This view rejects the idea that the quality and robustness of evidence would lie exclusively in its technical quality and in the independence of its producer, and instead calls attention to the processes of evidence-construction. From this perspective, strategic and political use of indicators, manipulation or even abuse of indicators is not necessarily a problem, but rather an essential part of the production of valid and reliable evidence.

Likewise, in explaining the use and influence of SDI-Cs, 'user factors' (beliefs and representations of policy actors) and 'policy factors' (institutional context) were crucial, whereas 'indicator factors' (quality of the indicators) played only a limited role. Our findings call to give greater attention to the various actors involved as well as to the general political and institutional contexts in which indicators are being produced.

Our results mirror the fact that SD is not a unifying policy idea at the EU-level. If there seems to be a consensus about the theoretical idea of SD, our analyses reveal that the ways to achieve SD are still controversial amongst producers of indicators, stakeholders and even amongst EU institutions. As SD is not (anymore?) the overarching policy framework at EU-level, SDI-Cs are rarely put forward; the current reference policy documents appear to be the Lisbon Strategy and the EU 2020 strategy rather than the EU-SDS. The little reference given to SD is acknowledged to be further fading out, and replaced little by little by a newer framework of reference, i.e. the policy idea of 'wellbeing'. At indicator level, the references to 'wellbeing' have been advocated and popularised prominently by the Stiglitz-Sen-Fitoussi report.

SDI-Cs are controversial because of the various visions of sustainability existing in the policy arenas. We show that SDI-C are ammunition at the service of various stakeholders to legitimise a particular political and societal agenda, i.e. their 'vision' 
of sustainability. SDI-C are 'framework indicators', enhancing the conceptual and symbolic influence of data. They are theory-driven and help discussing new paradigms without necessarily supporting systematic practical policy outputs. The objective is to reach shared understanding and policy learning. One positive effect is that SDI-C enhance discussions on the desirable state of our society and environment. On the other hand, these controversies limit the use of SDI-C because consensus is difficult to achieve regarding such indicators. These overall opposing viewpoints generate a relatively vague and unclear demand from policy makers for composite indicators. On the one hand, high-level policy makers seem to appreciate the fact that SDI-C are rather inadequate when it comes to design policies, but are relatively suited to capture rapidly the stakes of an issue. On the other hand, policy makers are being overwhelmed by indicators coming from all sides and presenting various facets of a policy problem.

There remain major gaps between indicator creators and users, leading to misunderstandings between actors. However, there were also internal quarrels within EU institutions about sustainability indicators. The different institutions at EU-level do not have the same visions of what should be measured regarding sustainability in Europe. As controversy remains within EU's institutions, many discussions are being run internally and SDI-Cs rather exacerbate existing policy conflicts between EU-institutions. Nevertheless, new types of governance processes are taking place in parallel of the EU-debate, led by what we call "middle actors". SDI$\mathrm{C}$ are currently being proposed actively by these types of actors (i.e. 'Intermediate'-actors such as NGOs, think tanks, scientists, etc.) to decision makers as well as to citizens. We refer to these percolation processes as being 'middle-up' and 'middle-down' indicators. This latter observation should be given further attention by future explorations: indicator pathways through social networks and the longitudinal study of the percolation from one policy actor-level to another might well provide for a further important refinement of the policy use of composite indicators.

\section{Acknowledgments}

The present paper is a synthesis of some of the results acquired during the POINT (Policy influence of Indicators) project financed under the European Commission's 7th Framework program (Grant Agreement number 217207). More information and material can be obtained at: www.POINT-EUFP7.info. We would like to thank the 2 anonymous reviewers for their constructive feedback on an earlier draft.

\section{References}

Amara, N., Ouimet, M., Landry, R., 2004. New evidence on instrumental, conceptual, and symbolic utilization of university research in government agencies. Sci. Commun. 26 (1 (September)), 75-106.

Ayres, R.U., 2000. Commentary on the utility of the ecological footprint concept. Ecol. Econ. 32, 347-349.

Bauler, T., 2012. An analytical framework to discuss the usability of (environmental) indicators for policy. Ecol. Indic. 17, 38-45

Boulanger, P.-M., 2007. Political uses of social indicators: overview and application to sustainable development indicators. Int. J. Sust. Dev. 10 (1-2), 14-32.

Cash, D., Clark, W., Alcock, F., Dickson, N., Eckley, N., Jäger, J., 2002. Salience, Credibility, Legitimacy and Boundaries: Linking research, assessment and decision making. In: John F. Kennedy School of Government, Harvard University, Faculty Research Working Papers Series (November 2002 (RWP02-046)).

Cash, D.W., Clark, W.C., Alcock, F., Dickson, N.M., Eckley, N., Guston, D.H., Jager, J., Mitchell, R.B., 2003. Knowledge systems for sustainable development. Proc. Natl. Acad. Sci. 100, 8086-8091.

CEC-COM, 2009. GDP and beyond; measuring progress in a changing world. Communication from the Commission to the Council and the European parliament, 433 final.

Chateauraynaud, F., 2011. Argumenter dans un champ de forces. Essai de balistique sociologique, Pétra, Paris.
Devitt, J., DeFusco, D., 2002. Finland Ranks Highest in Environmental Index; U.S. Lags. In: Press Release of the Environmental Sustainability Index project. http://www.ciesin.columbia.edu/indicators/ESI/press_rel.html

FAIR manifesto, 2008. From a "some have much" society to a sustained "well-beingfor-all" society. FAIR (Forum for other Indicators of wealth) (coordinated by Helene Combe).

Fraser, E., Dougill, A.J., Mabee, W.E., Reed, M., McAlpine, P., 2006. Bottom up and top down: analysis of participatory processes for sustainability indicator identification as a pathway to community empowerment and sustainable environmental management. J. Environ. Manag. 78 (2), 114-127.

Flyvbjerg, B., 1998. Rationality and Power: Democracy in Practice. University of Chicago Press, Chicago, IL.

Gahin, R., Veleva, V., Hart, M., 2003. Do indicators help create sustainable communities? Local Environ. 8 (6), 661-666.

Gallopin, G.C., 1996. Environmental and sustainability indicators and the concept of situational indicators. A systems approach. Environ. Model. Assess. 1, 101-117.

Gudmundsson, H., 2003. The policy use of environmental indicators - learning from evaluation research. J. Transdisciplinary Environ. Stud. 2 (2), 1-12.

Hardi, P., Zdan, T., 1997. Assessing Sustainable Development: Principles in Practice. International Institute for Sustainable Development, Winnipeg.

Mark, M.M., Henry, G.T., 2003. Beyond use: understanding evaluation's influence on attitudes and actions. American Journal of Evaluation 24 (3), 293-314.

Hezri, A.A., Dovers, S.R., 2006. Sustainability indicators, policy, governance: issues for ecological economics. Ecol. Econ. 60, 86-99.

Holden, M., 2008. Social learning in planning: seattle's sustainable. Development codebooks. Progr. Plan. 69 (2008), 1-40.

Illner, M., 1984. On functional types of indicators in social planning. Soc. Indic. Res. 14 (3), 275-285.

Innes, J.E., Booher, D.E., 2000. Indicators for sustainable communities: a strategy building on complexity theory and distributed intelligence. Plan. Theory Pract. $1(2), 173-186$.

Innes, J.E., 1998. Information in communicative planning. J. Am. Plan. Assoc. 64 (1), $52-63$

Joint Research Center(JRC), 2010. Indicators for Lisbon post-2010. Business as usual? JRC Scientific and technical reports (EUR 57104).

Kingdon, J.W., 1984. Agendas, Alternatives and Public Policies. Little Brown, Boston.

Lehtonen, M., 2004. The environmental-social interface of sustainable development: capabilities, social capital, institutions. Ecol. Econ. 49, 199-214.

Lehtonen, M., 2005. OECD Environmental performance review programme: accountability (f)or learning? Evaluation 11 (2), 169-188.

Leknes, E., 2001. The roles of EIA in the decision-making process. Environmental Impact Assessment Review 21 (4), 309-334.

McCool, S.F., Stankey, G.H., 2004. Indicators of sustainability: challenges and opportunities at the interface of science and policy. Environ. Manag. 33, 294-305.

Ortega-Cerdà, M., 2005. Sustainability indicators as discursive elements. In: Paper presented at the 6th International Conference of the European Society for Ecological Economics, Lisbon http://ecoman.dcea.fct.unl.pt/projects/esee2005 (accessed 13.03.09)

Ostrom, E., 1999. Institutional rational choice: an assessment of the IAD framework. In: Paul, S. (Ed.), Theories of the Policy Process. Westview Press 1997, Boulder, $\mathrm{CO}$.

Organisation for Economic Cooperation Development (OECD), 2011. How's life? Measuring Wellbeing. OECD, Paris.

Owens, S., Rayner, T., Bina, O., 2004. New agendas for appraisal: reflections on theory, practice, and research. Environ. Plan. A 36 (11), 1943-1959.

Parris, T., Kates, R., 2003. Characterizing and measuring sustainable development. Ann. Rev. Environ. Res. 28 (13), 1-28.

Patton, M., 1997. Utilization-Focused Evaluation: The New Century Text. Sage, Thousand Oaks, CA.

Pielke, R.A., 2007. The Honest Broker: Making Sense of Science in Policy and Politics. Cambridge University Press.

Pollitt, C., 2006. Performance information for democracy. Miss. Link? Eval. 12 (1), $39-56$.

Pregernig, M., 2000. Putting science into practice: the diffusion of scientific knowledge exemplified by the Austrian 'Research Initiative Against Forest Decline'. For. Policy Econ. 1 (2), 165-176.

Rice, J., 2003. Environmental health indicators. Ocean Coastal Management 46, 235-259.

Romsdahl, R.J., 2005. Political Deliberation and E-Participation in Policy-Making. CLCWeb: Comparative Literature and Culture 7.2. http://docs.lib.purdue.edu/ clcweb/vol7/iss $2 / 7$

Rosenström, U., 2006. Exploring the policy use of sustainable development indicators: interviews with Finnish politicians. J. Transdisciplinary Environ. Stud. 5 (1-2) http://www.journal-tes.dk

Rosenström, U., Lyytimäki, J., 2006. The role of indicators in improving timeliness of international environmental reports. Eur. Environ. 16, 32-44.

Rydin, Y., 2007. Re-examining the role of knowledge within planning theory. Plan. Theory 2007, 52-68.

Sabatier, P., 1991. Political science and public policy. Polit. Sci. Polit. 24, 144-146.

Sager, T., Ravlum, I.A., 2005. From projects to strategies: a transaction cost approach to politicians' problems with strategic transport planning. Plan. Theory Pract. 6 (2 (June)), 213-232. 
L. Sébastien, T. Bauler / Ecological Indicators 35 (2013) 3-12

Sebastien, L., Bauler, T., 2010. Is there a real demand for composite indicators for sustainability? In: Proceedings of the International Conference of Ecologica Economics, Oldenburg, August 22-26.

Sonntag, V., 2010. Designing Sustainability Indicator Frameworks for Information Flow: A Case Study of B-Sustainable. In: Applied Research Quality Life, The International Society for Quality-of-Life Studies (ISQOLS) 2010.

Stiglitz, J.E., Sen, A., Fitoussi, J.-P., 2010. Mismeasuring our lives. Why GDP doesn't add up. In: The Report by the Commission on the Measurement of Economic Performance and Social Progress. New Press, New York/London.

Turnhout, E., Hisschemöller, M., Eijsackers, H., 2007. Ecological indicators: between the two fires of science and policy. Ecological Indicators 7, 215-228.

Valovirta, V., 2002. Evaluation utilization as argumentation. Evaluation 8 (1), 60-80
Van der Knaap, P., 2006. Responsive evaluation and performance management. Overcoming the downsides of policy objectives and performance indicators. Evaluation 12 (3), 278-293.

Van der Meer, F.-B., 1999. Evaluation and the social construction of impacts. Evaluation 5, 387-406.

Vedung, E., 1997. Public Policy and Program Evaluation. Transaction Publishers, New Brunswick (NJ), USA.

Weiss, C., Murphy-Graham, E., Birkeland, S., 2005. An alternate route to policy influence: how evaluations affect D.A.R.E. Am. J. Eval. 26 (1), 12-30.

Weiss, C., 1999. The interface between evaluation and public policy. Evaluation 5 (4), 468-486. 